\title{
Propostas curriculares Estaduais para Educação Física: uma análise do binômio intencionalidade-avaliação ${ }^{1}$
}

\author{
Kadja Michele Ramos Tenório ${ }^{1,2}$ \\ Brígida Batista Bezerra ${ }^{2}$ \\ Marcílio Souza Júnior ${ }^{1}$ \\ Pierre Normando Gomes-da-Silva ${ }^{2,3}$ \\ Marcelo Soares Tavares de Melo ${ }^{1,4}$

\begin{abstract}
${ }^{1}$ Grupo de Pesquisa Estudos Etnográficos em Educação Física e Esportes (ETHNÓS), Escola Superior de Educação Física, Universidade de Pernambuco, Recife, PE, Brasil

${ }^{2}$ Grupo de Estudos e Pesquisas sobre Corporeidade, Cultura e Educação (GEPEC),

Escola Superior de Educação Física, Universidade de Pernambuco, Recife, PE, Brasil

${ }^{4}$ Colégio de Aplicação, Universidade Federal de Pernambuco, Recife, PE, Brasil
\end{abstract} \\ ${ }^{3}$ Centro de Ciências da Saúde, Universidade Federal da Paraíba, João Pessoa, PB, Brasil
}

\begin{abstract}
Resumo: Este trabalho analisou a coerência interna entre as intencionalidades e as avaliações contidas em propostas curriculares Estaduais para educação física escolar do sudeste brasileiro. Caracterizou-se como um estudo documental de abordagem qualitativa que teve como fonte dos dados as propostas curriculares disponibilizadas digitalmente. Estes foram tratados a partir da análise de conteúdo categorial por temática. Reconhecemos incoerência entre os elementos intencionalidade e avaliação, sendo estes trabalhados como partes independentes no processo de ensino-aprendizagem, exceto nas propostas do Espírito Santo e Rio de Janeiro. Encontramos, majoritariamente, a utilização dos termos competências e habilidades, vinculados à busca por resultados quantitativos em sistemas avaliativos no âmbito nacional, em detrimento das conquistas qualitativas no cenário educacional. Ainda que tenhamos feito análise documental acreditamos que o binômio intencionalidade-avaliação pode/deve ser melhor refletido/elaborado para que o processo/produto da aprendizagem se torne significativo para a formação do aluno e não visto apenas como números atingidos ou documentos inócuos.
\end{abstract}

Palavras-chave: Educação Física. Currículo. Intencionalidade. Avaliação.

\section{Proposals for state Physical Education curriculum: analysis-evaluation intentionality of the binomial}

\begin{abstract}
This study examined the internal consistency between intentions and assessments contained in proposals to state curricular physical education in southeastern Brazil. Characterized as a desk study of qualitative approach was used as a source of data available digitally curricular proposals. These were treated as categorical content analysis by theme. We recognize the inconsistency between intention and evaluation elements, and they worked as independent parties in the process of teaching and learning, except in the proposals of the Holy Spirit and Rio de Janeiro. We find, mostly, to use the terms competencies and skills related to the search for quantitative results in the national systems of evaluation at the expense of qualitative achievements in the educational setting. Although we did document analysis we believe that the binomial intentionality-assessment can / should be better reflected / prepared for the process / product of learning to become meaningful to the student's education and not just seen as innocuous documents or hit numbers.
\end{abstract}

Keywords: Physical Education. Curriculum. Intentionality. Evaluation.

\footnotetext{
${ }^{1} \mathrm{O}$ presente trabalho faz parte de uma pesquisa intitulada: proposta curricular em educação física escolar: uma análise a partir da prática pedagógica, financiada pela Capes na modalidade bolsa de stricto-senso. Esta por sua vez constitui um subprojeto da pesquisa "A Prática Pedagógica da Educação Física em diferentes segmentos escolares", aprovada pelo Comitê de Ética em Pesquisa da UPE em setembro de 2008 com Registro no Comitê de Ética em Pesquisa da UPE 139/08. Registro do Caae (Certificado de Apresentação para Apreciação Ética): 0131.0.097.000-08. Tal projeto está vinculado à linha de pesquisa Prática Pedagógica e Formação Profissional em Educação Física do Programa Associado de Pós-Graduação em Educação Física - Mestrado da UPE/UFPB e contou com financiamento pelo Termo de Convênio de Cooperação Técnica e Financeira (n. 033/2010) entre a UPEESEF-Ethnós e a Secretaria de Educação do Estado de Pernambuco.
}

\section{Introdução}

\section{Aproximação com o objeto de estudo}

A partir da década de 1960 as teorias tradicionais de currículo, no cenário mundial, passaram a ser postas em xeque. Nas décadas posteriores de 1970 e 1980, através das teorias críticas, e a partir da década de 1990, com as teorias pós-críticas novas e diferentes formas de pensar o currículo, passam a, respectivamente, explicitar as contradições macro e microssociais, 
retirando seus focos das questões técnicas de como fazer um currículo, negando sua neutralidade política e ideológica.

Essas novas teorias curriculares passaram a questionar o próprio currículo, as relações de poder que ele representa em relação à cultura, etnia, gênero, classe social etc. Entre as contribuições oriundas desse período Silva (2011), salienta um número significativo de teóricos que contribuíram para esse novo delineamento curricular, entre eles, destacam-se: Michael Young, Michael Apple, Henri Giroux, Ivor Goodson, Paulo Freire, Dermeval Saviani, José Carlos Libâneo, Antonio Flávio Moreira.

Especificamente no Brasil, em paralelo às discussões acerca dessas teorias e, particularmente, na mais recente estruturação curricular nacional da Educação Básica, contamos com reformulações orientadas por questões legais a partir da promulgação da Lei de Diretrizes e Bases da Educação (LDB) $\underline{9.394 / 96}$ que expressa em seu Art. 26 que:

Os currículos do ensino fundamental e médio devem ter uma base nacional comum, a ser complementada, em cada sistema de ensino e estabelecimento escolar, por uma parte diversificada, exigida pelas características regionais e locais da sociedade, da cultura, da economia e da clientela (BRASIL, 1996).

Ainda que a referida legislação educacional apresente conflitos e contradições, de trajetória e de conteúdo, percebe-se que uma possibilidade e necessidade de elaboração e implementação curricular por parte dos docentes, se apresentou nos últimos anos, diferenciando-a das demais LDBs. Mesmo que de forma controlada, ou até mesmo falseada, é possível e necessário, a partir da Lei $n . .9$ 9.394/96, superar os currículos prescritos pelas instâncias centrais e oficiais de governo ou mesmo pelos estudiosos no assunto.

Procurando superar uma época em que os currículos eram construídos por especialistas (legisladores ou intelectuais) - curriculistas - e apresentados às escolas e aos professores para serem seguidos como guias curriculares, por vezes até com padrão nacional, esse novo contexto coloca os professores, não especialistas em currículo, frente a várias maneiras de compreendê-lo, enfrentando também, formas de construí-los.

Entre os desdobramentos, com esta diferenciação desta Lei, nos anos seguintes, emergiram várias orientações políticas para educação como, por exemplo, o Decreto $\mathrm{n}^{\circ}$ 6.094/07 mais conhecido como Movimento Todos pela Educação que estabelece metas relacionadas à qualidade da educação a serem alcançadas para que o Brasil possa ser considerado independente até 0 ano do bicentenário da Independência em 2022. E a Resolução $n . .4$ de 13 de julho de 2010, onde define diretrizes curriculares nacionais gerais para a Educação Básica e deixa claro esta possibilidade de participação docente na elaboração curricular, como vemos:

Art. 13. O currículo, assumindo como
referência os princípios educacionais
garantidos à educação, assegurados no artigo
$4^{\circ}$ desta Resolução, configura-se como o
conjunto de valores e práticas que
proporcionam a produção, a socialização de
significados no espaço social e contribuem
intensamente para a construção de identidades
socioculturais dos educandos. [...] § 3ํ A organização do percurso formativo, aberto e contextualizado, deve ser construída em função das peculiaridades do meio e das características, interesses e necessidades dos estudantes, incluindo não só os componentes curriculares centrais obrigatórios, previstos na legislação e nas normas educacionais, mas outros, também, de modo flexível e variável, conforme cada projeto escolar, e assegurando: [...]

III- escolha da abordagem didático-pedagógica disciplinar, pluridisciplinar, interdisciplinar ou transdisciplinar pela escola, que oriente 0 projeto político-pedagógico e resulte de pacto estabelecido entre os profissionais da escola, conselhos escolares e comunidade, subsidiando a organização da matriz curricular, a definição de eixos temáticos e a constituição de redes de aprendizagem (BRASIL, 2010) (grifos nossos).

Ambas as formas de subsídio para as reformulações curriculares (legal ou política) direcionam para a construção tanto de currículos em um sentido geral, quanto de propostas curriculares em um sentido específico; e, aqui, nos interessa, em particular, as propostas curriculares de educação física escolar.

Nesse contexto, faz-se necessário diferenciarmos nossa compreensão de currículo e proposta curricular sem que um descarte o outro, pois compõem o mesmo fenômeno da política e prática educacional. Entendemos que o primeiro é algo mais amplo, atendendo a generalidades educacionais, uma diretriz. Resulta de um processo de seleção, de produção de saberes, de 
visões de mundo, de habilidades, de valores, de símbolos e significados, de relação de poder, de expressão cultural, de uma identidade, de uma determinada trajetória capaz de expressar formas de organização do conhecimento selecionado (LOPES, 1999; SOUZA JÚNIOR, 2007, 2011; SILVA, 2011). Já a proposta curricular tem origem no currículo sendo mais específica, operacional, estabelecendo uma relação mais próxima com o projeto político pedagógico da escola onde será vivenciada, expressando elementos como: contexto histórico, intencionalidade, conteúdos, aspectos metodológicos e avaliação.

Atendendo as orientações legais e incorporando políticas educacionais, alguns dos Estados e o Distrito Federal passaram a construir suas propostas curriculares. Partindo dessas recentes reformulações e da centralidade do currículo nos debates educacionais, em especial a partir da década de 1990, alguns estudos desenvolvem-se na educação física, tomando diferentes eixos de análise como a diversidade cultural (NEIRA; NUNES, 2008; NEIRA et al., 2012), ou mesmo voltam-se para a análise de propostas específicas (MARTINY et al., 2011), e alguns versando sobre a dificuldade de materialização dos currículos (SANTOS, 2007).

Nós optamos, nesse estudo, por analisar a relação estabelecida entre os elementos intencionalidade e avaliação nas propostas curriculares, inspirando-nos nas reflexões de Freitas (1995).

O autor acima estuda, enquanto categoria, o par dialético, o binômio objetivo-avaliação, apontando-o como um possível pivô do poder da organização do trabalho pedagógico na escola capitalista. Pretendendo contrapor a uma frequente tentativa, no campo da didática, de construir uma proposta alternativa pela via da análise teórica, o autor acredita que:

a didática somente poderá ser superada à medida que parta das próprias contradições existentes na escola capitalista. Para tal, será necessário um esforço no sentido de construirmos um sistema de categorias que dê conta de tais contradições e abra possibilidades de superação (REITAS, 1995, p. 12).

Os elementos intencionalidade e avaliação tem estruturado a maioria das propostas Estaduais disponíveis digitalmente no Brasil. Entretanto, é necessário esclarecermos que o uso do termo intencionalidade foi uma opção nossa, uma vez que as propostas curriculares não apresentam regularidade no uso dos termos objetivo, competências e habilidades. Todavia, a forma como esses termos são postos nos permitem englobá-los na categoria intencionalidade, que, conforme Ferreira (2010), significa que há uma intenção, nesse caso, uma intenção educacional. Sendo assim, utilizaremos intencionalidade englobando objetivos, habilidades e competências.

Levamos em consideração que para alguns autores (TYLER, 1974; CASTANHO; CASTANHO, 2010; PILETTI, 2010), os objetivos se referem às mudanças/resultados que se buscam atingir por meio da aprendizagem. Já o termo competências faz referência à capacidade de o aluno mobilizar e fazer uso em contextos diversos das habilidades conquistadas. Por sua vez, habilidades compreendem a capacidade de realização de determinadas tarefas ${ }^{2}$.

A utilização, cada vez mais frequente, no cenário brasileiro dos termos competências e habilidades, em especial nas propostas curriculares, acompanham as orientações contidas na LDB 9.394/96, quando faz referência a necessidade dos alunos construírem, na Educação Básica, capacidades relacionadas ao currículo de uma forma geral e associa-se às políticas avaliativas brasileiras (Exame Nacional do Ensino Médio, Sistema de Avaliação da Educação Básica, entre outras). Essas nossas considerações ratificaram a possibilidade de usarmos aqui, sem prejuízo para o estudo, o termo intencionalidade como termo que faz referência aos objetivos, competências e habilidades apresentadas pelas propostas Estaduais.

Quando nos reportamos a o outro elemento, objeto de nossa análise, a avaliação, encontramos Piletti (2010), apontando que ela consiste em um processo contínuo de interpretação dos conhecimentos, habilidades e atitudes dos alunos focando-se as mudanças almejadas pelos objetivos. Já para Sacristàn (1998), a avaliação expressa um juízo de valor, por parte do professor, direcionando-o para uma decisão a partir da coleta de determinados indícios. Luckesi (1998), acrescenta que a avaliação não possui um fim em si mesma, ela norteia ações que buscam atingir resultados previamente definidos, as intencionalidades.

Concordamos com Luckesi (1998), quanto ao reconhecimento da existência de uma relação direta e complementar entre intencionalidade e avaliação, relação essa que pode se configurar

\footnotetext{
2 Sabemos que há diferenças nas teorias pedagógicas que fundamentam estas distintas formas de estabelecer as intencionalidades pedagógicas, entretanto não é nosso objeto de estudo. Sugerimos consultar Souza Júnior (2007).
} 
enquanto binômio condutor do processo de ensino-aprendizagem.

Ao considerarmos o binômio intencionalidadeavaliação, estamos de acordo com Freitas (1995), identificando sua indissociabilidade e reconhecendo a relação dialética entre si. Essa relação dialética torna-se importante na medida em que permite verificar até que ponto as intencionalidades estão sendo alcançadas, retroalimentando 0 processo de ensinoaprendizagem, diagnosticando as fragilidades $\mathrm{e}$ avanços na construção dos saberes.

Desta forma, este artigo objetiva analisar as propostas curriculares Estaduais para o ensino da educação física escolar (EFE), especificamente, a relação entre o binômio intencionalidadeavaliação. Para analisar essa relação buscamos responder as questões: 1- Quais as intencionalidades apresentadas pela proposta para educação física escolar? 2- Os métodos e instrumentos avaliativos expressos na proposta dão conta das intencionalidades?

Assim, consideramos importante esta análise por entendermos que dessa maneira estaremos contribuindo para que a prática pedagógica não se fundamente em intencionalidades aleatórias, desarticuladas de formas e instrumentos avaliativos.

\section{Métodos}

O presente estudo compreende uma pesquisa do tipo documental, pois "[...] o conteúdo dos textos (jornais, gravações documentos oficiais) ainda não tiveram nenhum tratamento analítico, são ainda matéria-prima, a partir do qual o pesquisador vai desenvolver sua investigação e análise" (SEVERINO, 2007, p.122 e 123). As fontes do nosso estudo são documentos oficiais oriundos de órgãos estatais brasileiros, como as Secretarias de Educação. Quanto à abordagem, classificamos como qualitativa uma vez que nossa intenção foi fazer uma análise entre categorias (intencionalidade e avaliação) expressas nas propostas curriculares para educação física, mais apreensível de forma descritiva e interpretativa. Nossa opção por essa abordagem se deu pela possibilidade de investigarmos um universo repleto de significações, atitudes, crenças e valores que necessitam de uma análise que ultrapasse as questões numéricas (MINAYO, 2004).

Quadro 1. Mapeamento geral das propostas curriculares para Educação Física Escolar disponibilizadas digitalmente, por regiões e Estados.

\begin{tabular}{|l|l|l|}
\hline Região & Situação da proposta & Ano de publicação \\
\hline Norte & & \\
\hline Rondônia & Disponível & 2010 \\
\hline Acre & Disponível & 2010 \\
\hline Amazônia & Não disponível & \\
\hline Roraima & Não disponível & \\
\hline Pará & Não disponível & \\
\hline Amapá & Não disponível & \\
\hline Tocantins & Não disponível & \\
\hline Nordeste & & 2009 \\
\hline Maranhão & Disponível & \\
\hline Piauí & Não disponível & \\
\hline Ceará & Não disponível & \\
\hline Rio Grande do Norte & Não disponível & \\
\hline Paraíba & Não disponível & 2010 \\
\hline Pernambuco & Disponível & \\
\hline Alagoas & Não disponível & 2007 \\
\hline Sergipe & Disponível & \\
\hline Bahia & Não disponível & \\
\hline Sudeste & & Não informado \\
\hline Minas Gerais & Disponível & 2009 \\
\hline Espírito Santo & Disponível & 2010 \\
\hline Rio de Janeiro & Disponível & 2010 \\
\hline São Paulo & Disponível & \\
\hline Sul & & 2008 \\
\hline Paraná & Disponível & Não informado \\
\hline Santa Catarina & Disponível & 2009 \\
\hline Rio Grande do Sul & Disponível & \\
\hline Centro-oeste & & 2010 \\
\hline Mato Grosso & Não disponível & \\
\hline Goiás & Não disponível & \\
\hline Distrito Federal & Disponível & \\
\hline Mato Grosso do Sul & Não disponível & \\
\hline & & \\
\hline
\end{tabular}


Utilizamos como critério de inclusão das propostas Estaduais ${ }^{3}$, nesse estudo, o fato de serem disponibilizadas em versão digital on-line nos sites das respectivas Secretarias de Educação. A coleta dos dados nos sites foi realizada no período de março a maio de 2011. Os dados encontrados foram organizados em quadros por regiões, como vemos no quadro 1 , que indicam que identificamos 13 propostas curriculares em EFE atendendo ao critério de inclusão.

Dentre esses Estados, recortamos a região que apresentou o maior número de propostas e que os anos de publicação foram mais recentes. Subentendendo que essa data recente reflete uma maior proximidade com 0 atual contexto acadêmico-científico da EFE. Dessa forma, passamos a trabalhar apenas com as propostas da região sudeste, ainda que nessa região haja um Estado, Minas Gerais, que não especifica sua data de publicação.

Após a leitura de tais propostas na íntegra, a organização dos dados foi feita por meio da construção de quadros analíticos contemplando as categorias: educação física escolar, currículo e prática pedagógica. A categoria EFE possuiu enquanto unidades de contexto: papel da educação física, objeto de estudo, objetivo e referencial teórico. Já a categoria currículo teve as seguintes unidades de contexto: concepção, fonte, organização dos saberes e conteúdos. E a última categoria, prática pedagógica, foi composta pelas unidades de contexto: aspectos metodológicos e avaliação.

Os dados foram tratados a partir da análise de conteúdo do tipo categorial de Bardin (2011), uma técnica formada por um conjunto de instrumentos metodológicos aplicados a discursos (conteúdos e continentes) diversificados. Essa opção de tratamento dos dados nos possibilitou (des)construir e (re)construir as relações estabelecidas entre o binômio intencionalidade-avaliação no interior

\footnotetext{
3 Esclarecemos que existem algumas propostas não disponíveis em versão digital, ou que estão parcialmente disponíveis como, por exemplo, o Estado de São Paulo que apenas disponibilizou no site da SE o seu caderno introdutório, não sendo por esse motivo, nesse estudo, analisados elementos contemplados em outros materiais que circulam internamente na rede, tais como os cadernos dos alunos e dos professores.
}

das propostas curriculares em educação física estudadas, como vemos no quadro 2.

Quadro 2. Presença explícita dos elementos didáticos intencionalidade e avaliação.

\begin{tabular}{|l|l|l|}
\hline Estado & Intencionalidade & Avaliação \\
\hline Minas Gerais & Sim $^{*}$ & Sim \\
\hline Espírito Santo & Sim $^{* *}$ & Sim \\
\hline Rio de Janeiro & Sim $^{*}$ & Sim \\
\hline São Paulo & Sim $^{*}$ & Não \\
\hline
\end{tabular}

* A proposta trabalha a partir da lógica das habilidades/competências.

${ }^{* *}$ A proposta trabalha a partir da lógica dos objetivos.

\section{Uma análise a partir das propostas} estaduais para Educação Física Escolar: intencionalidade e avaliação

Vimos que a região sudeste é a que possui maior número proporcional de Estados com propostas curriculares para educação física com data de publicação mais recente, dentre as propostas digitalmente disponíveis. Desta forma, exploramos as propostas dos Estados de Minas Gerais (s/d), Espírito Santo (2009), Rio de Janeiro (2010a, 2010b), e São Paulo (2010), confrontando internamente o objeto de estudo, as intencionalidades, as fontes utilizadas para a seleção dessas, e ainda os métodos e instrumentos utilizados para a avaliação das intencionalidades, com o intuito de evidenciar as relações que estão sendo estabelecidas entre o binômio intencionalidade-avaliação.

A proposta Estadual de Minas Gerais (s/d), para educação física, voltada para os anos finais do Ensino Fundamental II e para o Ensino Médio, corresponde a uma segunda versão da proposta inicial. Essa versão atual é resultado de avaliações ocorridas no ano de 2005 pelos professores da rede e por um grupo de assessores, e tenta se aproximar mais das condições atuais das escolas. Vale salientar que não encontramos nessa proposta o seu ano de publicação, bem como nenhuma informação sobre o ano de publicação da primeira versão.

No que concernem as intencionalidades, Minas Gerais (s/d), optou por se organizar a partir da lógica das habilidades, buscando desenvolver algumas tidas como imprescindíveis para os alunos nos diferentes níveis de ensino (MINAS GERAIS, s/d). A opção de Minas Gerais por trabalhar com habilidades foi fundamentada através da LDB (9.394/96), em seu Art. $32^{\circ}$ inciso III quando nos traz que o Ensino Fundamental, 
período de formação básica do cidadão, deve possibilitar ao aluno adquirir conhecimentos e habilidades (BRASIL, 1996). A proposta ainda utiliza-se das contribuições de Zabala (1998), para deixar explícito qual o entendimento acerca de competências e habilidades adotado nesse documento. Nesse contexto, a habilidade diz respeito a um saber fazer, enquanto que a competência se refere à capacidade do aluno em utilizar habilidades, conhecimentos e atitudes em diferentes situações.

Segundo Martiny et al., (2011), quando a proposta curricular trabalha na perspectiva de consecução das competências expressa-se uma forma de ruptura com modelos tecnicistas de currículo. A associação estabelecida entre a expressão das intencionalidades por meio de objetivos e os modelos tecnicistas de currículo está fundamentada em obras como a de Tyler (1974), onde a construção curricular se preocupava mais com a estrutura propriamente dita do que com os fins educacionais expressos pelo currículo.

A nosso ver, a utilização do termo competência ao invés de objetivo, por si só, não expressa ruptura com o modelo tecnicista. A presença do termo deve ser associada a outros aspectos como, por exemplo, a concepção de proposta curricular e de educação, para que possamos ter maior clareza quanto ao modelo que subsidia a proposta curricular.

Uma vez escolhida a orientação por meio das competências, a proposta de Minas Gerais (s/d), passou a listá-las e organizá-las a partir de quatro eixos temáticos para o Ensino Fundamental II e Médio, a saber: esporte, jogos e brincadeiras, ginástica, dança e movimentos expressivos (MINAS GERAIS, s/d). Dentro de cada eixo foram delimitados temas e tópicos, que nem sempre são os mesmos para o Ensino Fundamental II e Médio, e que representam níveis mais específicos para a organização do conhecimento.

Apesar de explicitar as habilidades relacionadas com cada um dos temas, não é possível identificar quais delas deverão ser trabalhadas em cada ano do Ensino Fundamental II e Médio. Partimos do pressuposto que o aprendizado, de forma geral, atende a uma ordem de complexidade que precisa ser respeitada durante 0 estabelecimento das intencionalidades. Souza Júnior et al., (2011), ressaltam a importância de existir critérios para a organização (hierarquização, sequência e graduação) das intencionalidades no intuito de favorecer o processo de aprendizagem. A nosso ver, quando a proposta opta por não expor quais habilidades devem ser trabalhadas assume o risco de ficar sem parâmetro para avaliar se o aluno alcançou as intencionalidades para aquela série.

A partir das habilidades selecionadas para cada um dos segmentos de Ensino (Fundamental II e Médio), inferimos que, no Ensino Fundamental II, a educação física tem como intencionalidade, de forma geral, que o aluno possua acúmulo de conhecimentos que possibilitem o trato com: questão histórica, de gênero, elementos técnicos, táticos, regras, risco e benefícios, classificações, vínculo com o contexto da saúde, lazer e qualidade de vida influência da mídia e diversidade cultural associados às diversas práticas corporais delimitadas pelos temas (esporte, jogos e brincadeiras, ginástica, dança e movimentos expressivos). Já para o Ensino Médio podemos apontar, de acordo com as habilidades estabelecidas pela proposta de Minas Gerais $(\mathrm{s} / \mathrm{d})$, que a intencionalidade geral para esse segmento de ensino trata-se da ampliação e aprofundamento das habilidades adquiridas durante o Ensino Fundamental II.

Posto as habilidades, passaremos a outro elemento objeto de nosso estudo, a avaliação. $\mathrm{Na}$ proposta de Minas Gerais identificamos uma compreensão de avaliação como instrumento verificador de características diversas, passível de aplicação para diferentes sujeitos envolvidos no contexto educacional, e que pode, portanto, servir a distintos objetivos, caracterizando um processo complexo e amplo.

No que concerne a avaliação o documento ainda a reconhece como sendo "parte intrínseca do processo de ensino-aprendizagem" (MINAS GERAIS, s/d, p.29), e que, a mesma, deve ser realizada pelo professor desde os primeiros contatos com os alunos para identificar os conhecimentos que esses últimos possuem. Esse encaminhamento avaliativo encontra consonância com aquilo que Zabala (1998), nos 
traz como avaliação formativa. Para ele a avaliação formativa compreende desde esse momento de diagnóstico inicial, passa pelas avaliações realizadas ao longo do processo, que podem até gerar uma reorganização na forma como os saberes estão sendo trabalhados, até chegar a denominada avaliação final que se refere à atribuição de valores/conceitos acerca do processo construído.

Em contrapartida à avaliação formativa, a proposta nos traz a avaliação podendo ser usada como forma de seleção de atletas. Esse direcionamento que faz uso da avaliação enquanto mero instrumento classificatório nos remete a um pensamento quantitativo que tem sua função voltada "para atender exigências burocráticas expressas em normas escolares, atender a legislação vigente e selecionar alunos para competições e apresentações (...)" (SOARES et al., 1992, p.98), e que não estabelece as devidas relações com as intencionalidades da proposta.

Retomando as intencionalidades, ratificamos a incoerência interna existente na proposta de Minas Gerais (s/d), no que concerne o binômio intencionalidade-avaliação, uma vez que a formação de atletas não esta entre as intencionalidades expressas, dessa forma, não deveria aparecer no momento avaliativo.

Esse hibridismo de processos avaliativos, desprovidos de uma relação entre eles, e, sobretudo, com as intencionalidades, denota uma fragilidade na fundamentação teórica, tendo em vista que a proposta de Minas Gerais (s/d), se subsidia do conceito de avaliação expresso por Sacristán (1998), entretanto não desenvolve uma avaliação pautada nas orientações desse autor, chegando a adotar um modelo criticado por ele. A fragilidade da avaliação nessa proposta também pode ser identificada quando a mesma põe diversos focos para serem contemplados na avaliação sem, contudo, explicar como se dão essas diferentes avaliações, entre os focos citamos: a proposta curricular, o professor, o sistema educacional e o aluno. Alguns autores (KENSKI, 1995; SANT'ANNA et al., 1998), ressaltam o potencial da avaliação crítica permitir inferências acerca não só da aprendizagem dos alunos, mas também do trabalho dos professores, dos conteúdos, recursos, metodologia, e da proposta curricular, desde que haja clareza de como e quando esses focos serão contemplados nas avaliações. Tais autores ratificam nossa crítica quanto à fragilidade por falta de clareza na utilização de diversos focos pela proposta de Minas Gerais (s/d), para educação física escolar.

Essa proposta, ainda deixa explícita a necessidade de se construir uma avaliação que possua consonância com as avaliações usadas em programas de avaliação do ensino a nível nacional e estadual. Essa necessidade apontada pela proposta referencia-se em uma perspectiva neoliberal de educação, que segundo Moreira (2000), buscam atender a uma lógica mercadológica, a favor da estruturação de uma rede de avaliação dos sistemas de ensino.

Com relação aos instrumentos utilizados na avaliação, constatamos a indicação para o uso de variados instrumentos, desde que se mantenha a coerência entre a sua especificidade e a intencionalidade. Apesar de solicitar que haja coerência, a proposta não apresenta nenhum exemplo de como essa coerência pode ser alcançada. Pelo contrário, chega a expressar total incoerência entre alguns instrumentos avaliativos e as intencionalidades a que se propôs inicialmente.

Isto pode ser constatado quando a proposta apresenta a diferenciação entre instrumentos de medidas que ora tem como referência as normas e ora tem como referência o critério. No primeiro, os alunos são classificados a partir de uma ordem crescente em relação ao grupo. Já no segundo, a classificação é feita com relação aos outros desempenhos do próprio aluno. Com essa diferenciação a proposta ratifica que a primeira forma de avaliação é bastante útil para a seleção de atletas.

Dessa forma, percebemos que o direcionamento dado ao binômio intencionalidade-avaliação finca-se em incoerências que comprometem a consecução do que a proposta de Minas Gerais (s/d), propõe para o componente curricular educação física. $A$ incoerência se estende para a concepção de currículo adotada pela proposta de Minas Gerais (s/d), para EFE, e a desenvolvida ao longo da proposta, tendo em vista que o Estado defende o currículo

como um conjunto de experiências organizadas sistematicamente em dada realidade concreta, 
historicamente situada, destinado à formação de sujeitos autônomos, capazes de intervir na realidade e transformá-la segundo a ética democrática (MINAS GERAIS, s/d, p.31).

Conforme Silva (2011), a ideia defendida possui características da teoria crítica de currículo. Entretanto, a análise da proposta indica que no currículo possui mais proximidade com a busca de resultados em políticas avaliativas do que o defendido pelo currículo.

Agora, reportaremos à proposta para educação física do Estado do Espírito Santo (2009). Essa proposta contempla o segmento Fundamental I, II e Ensino Médio.

$\mathrm{Na}$ sua forma estrutural a intencionalidade é expressa pelo termo objetivo, que se encontra delimitado para cada um dos segmentos. Salientamos, contudo, que as intencionalidades são exatamente as mesmas para o Ensino Fundamental I, II e Médio.

Apesar de disponibilizar de forma clara suas intencionalidades, expressas na forma de objetivos da EFE, no momento de organizar os conteúdos a proposta se utiliza da ideia de competências e habilidades, distribuídas em cada série que, por sua vez, estão relacionadas com os seguintes eixos temáticos no Ensino Fundamental I: Conhecimento sobre o corpo; Corpo-linguagem/corpo-expressão; Os jogos e os movimentos individuais e coletivos. Para 0 Fundamental II e Médio mantém-se os eixos acima e há um acréscimo do eixo: jogo esportivo.

Fazemos a ressalva que assim como identificado nas intencionalidades as competências também são repetidas na maioria dos segmentos, havendo inserção de outras competências apenas no Ensino Médio no eixo corpo-linguagem/corpo-expressão. Para Schmitz (1982), a existência por si só de intencionalidades não é suficiente para a educação. É necessário que haja meios de operacionalizá-las considerando 0 contexto em que as intencionalidades estão inseridas, respeitando-se as características e o momento dos alunos durante o processo ensino-aprendizagem, dessa forma, não há respaldo critico para a repetição total ou parcial das competências e habilidades nos diferentes segmentos escolares.

Com relação à adoção de competências e habilidades 0 documento apresenta como justificativa ser esse o encaminhamento dado em documentos legais como os Parâmetros Curriculares Nacionais (BRASIL, 1998), e no instrumento avaliativo, também de âmbito nacional, o Exame Nacional do Ensino Médio. Essa justificativa sintética que não estabelece diálogo com um projeto educacional nos remete a denúncia de que os currículos e propostas curriculares para educação física, ainda expressam uma "pedagogia da eficiência" (VAGO, 1999, p.38), voltada para a busca de uma qualidade máxima da educação em termos quantitativos.

No Ensino Fundamental I, as competências e habilidades definidas mantém coerência interna com os objetivos anteriormente delimitados para esse segmento. Já no Fundamental II a coerência interna apresenta-se comprometida, uma vez que algumas habilidades estabelecidas não estão relacionadas com as competências, como também algumas competências não são contempladas nas habilidades. Quando nos reportamos ao Ensino Médio identificamos com relação ao primeiro eixo (conhecimento sobre o corpo) que o corpo abordado nas habilidades tem ênfase maior no corpo biológico, não se estabelecendo relação, por exemplo, com a questão de portadores de necessidades especiais como preconiza as competências. Nos demais eixos, encontramos alguns deslizes expressos na presença de habilidades relacionadas com competências que não estavam delimitadas. Pelo exposto acima apontamos a existência de uma coerência interna parcial entre intencionalidade, habilidade e competência para o Ensino Fundamental II e Médio.

As análises de como as intencionalidades estão estruturadas na proposta do Espírito Santo (2009), para EFE nos permite entender as competências e habilidades diferentemente da concepção definida por Zabala (1998), citada anteriormente, tendo em vista que os objetivos se configuram enquanto mudanças almejadas para o aluno (PILETTI, 2010), e as competências e habilidades seriam formas de operacionalizar tais mudanças. Essa compreensão pode ser

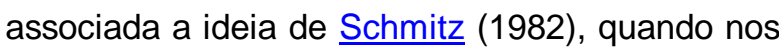
traz que a existência por si só de objetivos nos currículos não são suficientes para qualificar a educação, é necessário que se dê importância para operacionalização deles. 
Passaremos, nesse momento, ao que nos revela a avaliação presente na proposta. Para o Espírito Santo (2009), a avaliação é compreendida como parte intrínseca do processo ensino-aprendizagem e do projeto pedagógico. Dessa forma tece considerações que concernem à avaliação dos alunos, da instituição escolar e do próprio sistema educacional. No processo avaliativo deve conter uma avaliação diagnóstica de caráter formativo, possibilitando a reorientação do processo educativo, e a avaliação que expressa um resultado, denominada de somativa. A auto avaliação também é sugerida, no intento do aluno se sentir sujeito ativo em sua aprendizagem. Essa ideia é ratificada por Souza (2008), quando nos traz a avaliação, em uma perspectiva crítica, que supera a função classificatória, seletiva e passa a ser um eixo orientador da prática pedagógica mostrando caminhos, possibilitando ao professor refletir suas ações frente ao processo ensinoaprendizagem, bem como, a reflexão do aluno crítico e ativo no seu processo de aprendizagem.

Quanto aos instrumentos utilizados há indicações para que se use diversificados instrumentos (trabalhos, provas, testes, pesquisas, etc.) com a intenção de ampliar as possibilidades de captar as aprendizagens dos alunos. Ainda com relação aos instrumentos encontramos a solicitação para que os professores atentem para a qualidade dos instrumentos avaliativos que constroem. A proposta sintetiza seu entendimento a respeito do ato avaliativo expressando que:

A avaliação educacional realizada de forma sistemática, criteriosa e comprometida com o destino social dos indivíduos é um instrumento essencial para promover o debate público e favorecer a promoção de ações orientadas para a superação do fracasso e o fortalecimento da equidade e da democracia (ESPÍRITO SANTO, 2009, p.51).

Segundo a proposta o referencial teórico utilizado acerca da avaliação vem de um documento construído pelo Ministério da Educação, denominado Indagações sobre o currículo (BRASIL, 2007). Ao utilizar esse referencial teórico e indicar a apropriação dos professores desse material, a proposta do Espírito Santo (2009), sinaliza para o reconhecimento da importância do processo avaliativo frente à consecução das intencionalidades propostas. Esse material
"Indagações sobre o currículo" (BRASIL, 2007), apresenta pormenorizado o processo avaliativo, ressaltando os cuidados que o professor deve ter na condução desse processo, e a importância do mesmo enquanto elemento indispensável no para ensino e a aprendizagem escolar. Além da contribuição significativa para 0 andamento do binômio intencionalidade-avaliação no Estado do Espírito Santo (2009), o material "Indagações sobre o currículo" ainda possui o diferencial de ultrapassar a mera listagem de diversos instrumentos. Identificamos o comentário das potencialidades e fragilidades de cada um deles e exemplos entre as diferentes disciplinas de sua aplicabilidade.

De forma geral o que nos traz a proposta do Espírito Santo (2009), acerca da avaliação encontra consonância com a concepção dialética de avaliação considera por Romão (2009), onde os processos da avaliação precisam estar em interação dinâmica, consciente, processo e produto são elementos constitutivos de um mesmo fenômeno e pela conscientização o aluno e professor se reconhecem e se se modificam uns aos outros e a realidade que os envolve. Também identificamos coerência entre o entendimento da proposta acerca de currículo, entre seus elementos constituintes e a definição de um currículo crítico por Silva (2011), uma vez que ambos apontam o currículo enquanto espaço pedagógico para produção de identidades, de saberes, expressando relação de poder de história.

Nesse momento passaremos a proposta do Rio de Janeiro (2010, 2010). Essas propostas contemplam o Ensino Fundamental I, II e Médio.

O Estado opta por expor suas intencionalidades por meio de habilidades e competências, justificando sua opção com base nos grandes referenciais de avaliação em âmbito nacional que seguem essa perspectiva, mas, sobretudo, por entenderem que as habilidades e competências encerram "formas pelas os conteúdos e temas adquirem maior concretude, indicando ações resultantes do processo de ensino-aprendizagem, o que pode facilitar sua aplicação" (RIO DE JANEIRO, 2010a, s/p).

Nas Diretrizes encontramos os termos conceitos e competências como sinônimos de habilidades e competências. Essa sinonímia é por nós identificada quando nos reportamos à 
versão esquemática e lá estão elencadas exatamente as mesmas intencionalidades expressas pelas Diretrizes sob a nomenclatura de conceitos e competências.

A proposta expressa sua compreensão acerca de competência como a capacidade de mobilizar um ou mais conhecimentos para a solução de problemas, "o saber fazer" (RIO DE JANEIRO,2010b, p.28). Quanto ao entendimento de habilidades não há nada explícito.

Para Machado (2007), diferentemente do que aponta Zabala (1998), a habilidade possui estreita relação com competência, a ponto de em um determinado momento o que era tido como habilidade passar a ser competência, diferenciando-se, apenas, pelo contexto. Parecenos interessante que a proposta curricular para educação física do Rio de Janeiro (2010b), ao organizar-se por competências e habilidades, situe o contexto de tais termos na intenção de dirimir as confusões conceituais.

Especificamente, quanto às habilidades $\mathrm{e}$ competências, a proposta é bem genérica. Chega a não possibilitar, em algumas competências, o reconhecimento que pertencem à educação física, como exemplo, citamos: "Conhecer suas possibilidades e limitações, estabelecendo metas qualitativas e quantitativas pessoais" (RIO DE JANEIRO 2010b, p.146). Em sua maioria, as intencionalidades fazem referência à aspectos atitudinais ou habilidades sociais, como se expressa na proposta, aplicável a qualquer conhecimento. Já quando as especificidades são reconhecíveis, as intencionalidades estão voltadas para os jogos e brincadeiras, bem como intencionalidades para o desenvolvimento de condutas motoras.

Quando nos direcionamos ao Ensino Fundamental II as intencionalidades são organizadas apenas na forma de quadro, separadas por bimestres, e com delimitação de focos para cada um dos bimestres, direcionandose predominantemente ao esporte.

Para o Ensino Médio são delimitados outros focos voltados a cada ano e bimestre. Identificamos que as intencionalidades, na maioria dos focos, selecionadas são mais abrangentes que as selecionadas para o Ensino Fundamental, abordando aspectos históricos, conceituais, críticos, motores, técnicos, táticos.
Contudo, ainda há uma hegemonia das intencionalidades voltadas as questões motoras. Entretanto, algumas intencionalidades continuam a ser repetidas na íntegra desde o $6^{\circ}$ ano.

Para Freitas (1998), quando a proposta curricular estabelece interfaces com a realidade extraescolar associada aos conhecimentos, como na proposta do Rio de Janeiro (2010a), ao preocupar-se com o contexto histórico no qual um conhecimento é construído, sua avaliação deixa de ter como foco o produto da avaliação em termos conteudistas, e passa a explorar a riqueza do processo avaliativo dentro do trabalho pedagógico.

Uma vez posto as intencionalidades almejadas pela proposta do Rio de Janeiro (2010a), apresentaremos a avaliação. De forma sucinta nos é apresentado o quadro comparativo entre uma avaliação fundamentada na concepção classificatória e outra formativa. Explicitamente a proposta se posiciona pela utilização da formativa justificando que esse tipo de avaliação permite o acompanhamento de processo de ensino-aprendizagem, bem como, a formação geral do aluno (RIO DE JANEIRO, 2010b).

Também é explanado acerca dos instrumentos de registros que podem ser utilizados (portfólio, relatório, provas, testes, auto avaliação, exercícios individuais, entre outros) e suas funções.

Diante das intencionalidades expressas pelo Rio de Janeiro (2010a, 2010b), ainda que haja predominância das questões motoras, a opção do Estado em se subsidiar por uma avaliação formativa conforme Souza Júnior (2004), implica na oportunidade do aluno organizar e acompanhar sistematicamente os conhecimentos que esta construindo superando o modelo de educação física no qual apenas a avaliação motora é contemplada buscando-se a classificação entre os alunos.

Apesar da proposta do Rio de Janeiro (2010a, 2010b), para EFE não deixar explícito a teoria curricular em que se baseia podemos verificar a proximidade de entendimento de currículo enquanto "artefato social e cultural" (GOODSON, 1995, p.8) superando a visão tradicional em que - foco era a estrutura do currículo, negligenciando seus demais aspectos. 
O último Estado analisado foi o de São Paulo (2010), com proposta publicada no ano de 2010, voltada para o Ensino Fundamental II e Médio. A proposta expõe que suas intencionalidades serão apresentadas na forma de competências e justifica que se referem a "modos de ser, de raciocinar e de interagir, que podem ser depreendidos das ações e das tomadas de decisão em contextos de problemas, de tarefas ou de atividades" (SÃO PAULO, 2010, p. 12). A adoção do trabalho através de competências é respaldada em documentos legais como: LDB 9.394/96, PCNs e nas Diretrizes Curriculares Nacionais. Embora tenha feito esse registro, para - Ensino Médio verificamos que há uma definição de objetivos gerais e não de competências.

Essa confusão quanto à forma de expressar suas intencionalidades na proposta de São Paulo (2010), a nosso ver, denota uma fragilidade em seu argumento de sustentação, que representa mais adesão a uma tendência do uso do termo, do que a uma opção epistemológica. Sendo uma opção epistemológica deveria remeter a intencionalidade à teoria da Pedagogia de Competências, sustentada, por exemplo, por Phillip Perrenoud.

As competências são pensadas e elaboradas a partir de exigências mais complexas perante as ações de docentes e discentes e estabelecem uma metodologia mais ativa, participativa e problematizadora diante de contextos reais. [...] Podemos dizer que a estruturação das competências precisa expressar a capacidade do Aluno em solucionar problemas, pois elas constituem um fazer aprender (propiciar a aprendizagem), um aprender fazendo (aprender de forma dinâmica), um fazer aprendendo (dinâmicas críticas e contextualizadas), ou seja, reconhecem e materializam o agir pedagógico, numa interação entre os sujeitos e objeto da educação (PERNAMBUCO, 2006, p. 59).

Já os objetivos de ensino, remeteriam à Pedagogia dos Objetivos, fundamentada, por exemplo, nos estudos de Ralph Tyler ou Robert Mager, em que a intencionalidade expressa a ação esperada do aluno, o agir propriamente dito e mais objetivo, organizando esta num rigoroso processo de racionalização, fundada em estudos da psicologia comportamental, trazendo à instituição escolar uma visão instrumentalista do conhecimento.

Diferentemente do que foi identificado nas demais propostas analisadas, a do Estado de São Paulo (2010), não consta apenas de um quadro onde as intencionalidades são listadas. Ao longo do texto, há indicação de que os alunos que se encontram entre a $5^{\underline{a}}$ e a $8^{\underline{a}}$ séries do Fundamental devem identificar os significados e intencionalidades que envolvem seus acervos de experiências corporais do se movimentar, comparando com os sentidos e intencionalidades relacionadas com a cultura esportiva, lúdica, das lutas, expressões rítmicas e ginástica. Já para o Ensino Médio, as intencionalidades estabelecidas buscam a compreensão dos temas da cultura de movimento enquanto fenômenos socioculturais, contextualizados com a atualidade e realidade do aluno, de forma ampliada e que contribua com o desenvolvimento autônomo e crítico dos alunos.

Após isto ter sido estabelecido a proposta sintetiza as habilidades peculiares a educação física da seguinte forma:

[...] as habilidades identificar e reconhecer, desenvolvidas por meio dos eixos de conteúdos, são ampliadas ao longo da escolarização, para habilidades como relacionar e analisar. No Ensino Médio pretende-se que habilidades como apreciar, elaborar e intervir, desenvolvidas na interrelação entre os eixos de conteúdo e os eixos temáticos, contribuam para a construção da autonomia crítica e autocrítica do aluno (SÃO PAULO, 2010, p.185).

Com as intencionalidades identificadas passamos a buscar os direcionamentos referentes à avaliação, mas a proposta não contempla esse elemento, nem como tópico específico, nem enquanto considerações gerais ao longo do texto.

Entendemos que se houve a delimitação das intencionalidades frente às mudanças que se busca para o aluno ao longo de sua escolarização é imprescindível a presença de instrumentos e procedimentos que permitam acompanhar esse processo. Quando só há delimitação do que se fazer, sem uma avaliação, saímos do status de componente curricular e voltamos a ser mera atividade com significado restrito a ela mesma. Essa postura para Souza Júnior (2004), além de refletir no processo de ensino-aprendizagem põe em xeque a legitimação do componente curricular educação física.

Consideramos que "a avaliação desenvolvida no processo ensino aprendizagem deve estar vinculada a um projeto educativo mais amplo" (KENSKI, 1995, p. 136), esse projeto amplo está ligado tanto à relação escola e realidade social a 
qual ela se insere, como ao contexto nacional de onde emerge orientações e pressupostos teóricos para prática educativa. A falta do componente avaliação na proposta curricular de São Paulo (2010), acaba por romper o elo entre o contexto mais amplo e o processo de ensinoaprendizagem. É preciso, estar atento para os elos que envolvem as construções diretivas para educação física, pois as mesmas irão ser materializadas no saber e fazer pedagógico.

Posto a ausência total do elemento avaliação na proposta para EFE do Estado de São Paulo (2010), identificamos não só uma incoerência interna com relação às intencionalidades, mas, sim, uma lacuna expressiva na relação estruturante de elementos subsidiadores da prática pedagógica com implicações severas para um processo de ensino-aprendizagem qualitativo. Schmitz (1982), ratifica a importância da avaliação pondo-a como elemento indispensável frente ao processo de ensinoaprendizagem detentor da função de acompanhamento desde o planejamento das intencionalidades, a condução do processo pelos métodos, o uso das técnicas e recursos, até possíveis reorientações, quando necessárias, para que as intencionalidades sejam alcançadas. Pela ausência do elemento avaliação compromete-se, ainda, o diferencial positivo existente na proposta para EFE do Estado de São Paulo (2010), com relação às demais propostas da região sudeste, de ultrapassar a simples listagem de intencionalidades uma vez que seu acompanhamento foi renegado.

Ainda podemos apontar que a teoria curricular adotada pela proposta do Estado de São Paulo (2010), para EFE, mesmo que de forma não explícita, alicerça-se em uma visão liberal multiculturalista, na qual as diferenças culturais são absorvidas de forma pacífica (NEIRA; NUNES, 2008; SILVA 2011), sem que haja discussão sobre as relações de poder existente entre as diversas culturas.

\section{Considerações finais}

O currículo, nas últimas décadas dos séculos $X X$ e XXI, vem se constituindo como campo de discussões não consensual onde se disputam lógicas diferenciadas quanto a sua concepção e organização. Conforme Arroyo (2011), isso se deve ao papel central que o currículo ocupa enquanto estruturante da função da escolar, "por causa disso, é o território mais cercado, mais normatizado. Mas também o mais politizado, inovador, ressignificado" (ARROYO, 2011, p. 13).

Pertencentes ainda a esse universo político, a análise das propostas curriculares Estaduais para EFE, unidades mais específicas de cada área, nos revelaram acerca do binômio intencionalidade-avaliação que há falta de clareza teórica quanto à forma de organizar as intencionalidades, se por objetivos, se por competências/habilidades. A justificativa encontrada nas propostas para se subsidiarem pelas competências é, ainda que mascarada, a busca de compatibilidade com instrumentos nacionais de avaliação como o Sistema de Avaliação da Educação Básica e o Exame Nacional do Ensino Médio, denotando uma ideia mercadológica de ensino, sob a qual os aspectos quantitativos são priorizados em detrimento dos qualitativos.

Ao incorporar essa ideia, as propostas correm o risco de secundarizarem seu papel frente ao acompanhamento de questões qualitativas como: aspectos sociais, históricos e pessoais, fragilizando o papel crítico da educação contemporânea, como afirma Diniz e Amaral (2009), a forma como o sistema e o professor enxergam 0 aluno, seus conhecimentos, a relação entre os elementos constituintes do processo de ensino-aprendizagem, o papel da escola e a função do professor nesse contexto.

Quando a noção de competência é delimitada em função da força do mercado, ela é quase uma transposição linear e funcionalista dos resultados da investigação do processo de trabalho advindos do mundo econômico. Entretanto, quando se estabelece como elemento constituinte da subjetividade humana, elaborada no seio das contradições sociais, reconhecendo que tal força é uma expressão das mudanças ocorridas da sociedade, para, inclusive, poder compreendê-la criticamente e enfrentá-las, a competência assumindo uma postura crítica de reconhecimento do sujeito histórico corresponsável por suas transformações ( $\underline{\text { SOUZA }}$ JÚNIOR, 2011, p. 47, 54-55).

Acreditamos que devemos ir a busca da construção de um currículo/proposta curricular crítica e emancipatória, indo além da ampliação 
da empregabilidade de nossos alunos, sendo necessário consolidar uma formação humana para a sociabilidade, em que se faz necessário construir um sentimento de pertencimento e corresponsabilidade social, assim como apontar/elaborar estratégias para o engajamento coletivo e ético nos diferentes grupos sociais, tais como a escola, a família, o trabalho e tantos outros. A educação física é impreterivelmente elemento constituinte do currículo com esta aspiração social.

Apesar de termos abordado documentos curriculares oficiais que tratam de aspectos didáticos (intencionalidade e avaliação), enquanto orientações para a prática e a partir da prática, devendo nortear a ação pedagógica de gestores, professores e alunos e não a prática pedagógica em si, percebemos que há uma nítida fragilidade teórica diante desses elementos.

Inspirando-nos em Souza Júnior (2011), acreditamos que uma proposta curricular deve ser entendida, elaborada e utilizada como fonte epistemológica para a seleção, a organização e a sistematização dos saberes escolares. Numa rede de ensino, como é o caso dos 4 Estados objetos de análise deste estudo, uma proposta curricular deve ser objeto de referência da teoria e da prática pedagógica, permitindo acesso aos fundamentos e elaboração da ação docente, já que nesta os professores reconhecem as intencionalidades de sua área, de sua disciplina específica, dos eixos dos saberes, dos conteúdos e dos fundamentos metodológicos.

Lembramos ainda, que a utilização de competências e habilidades apenas vinculadas a instrumentos políticos, quer nas intencionalidades, quer nas avaliações reflete 0 pensamento de Souza (2008), quanto à deturpação dos seus significados pedagógicos desprovidos de articulação com o ensino, que são substituídos pela busca de índices considerados mínimos para um país desenvolvido.

De forma geral observamos que o binômio intencionalidade-avaliação mantém relação coerente nas propostas do Espírito Santo (2009), e Rio de Janeiro (2010a, 2010b), mas não mantém na de Minas Gerais (s/d). Já na proposta do Estado de São Paulo (2010), não há esta binômia, tendo em vista que o elemento avaliação não é contemplado.
Ainda que na proposta de Minas Gerais (s/d), encontremos indicações para que o binômio intencionalidade-avaliação esteja integrado, quando 0 analisamos, identificamos que os mesmos se mostram como elementos estanques.

$\mathrm{Na}$ proposta de São Paulo (2010), não podemos fazer esta análise, tendo em vista que a avaliação é totalmente negligenciada, possibilitando que julguemos as indicações das intencionalidades como mero cumprimento de formalidade didática, sem significarem as reais mudanças almejadas nos alunos.

Portanto, nesse momento de crescente atenção ao desenvolvimento e materialização de propostas curriculares para EFE no Brasil, apontamos a necessidade de se conceder maior atenção aos elementos intencionalidade e avaliação durante a construção das propostas Estaduais. Buscando, desta forma, dirimir as fragilidades quanto a coerência entre termos e referenciais epistemológicos, estabelecer as devidas relações entre os elementos didáticos intencionalidade e avaliação para que o processo e o produto da aprendizagem se tornem significativos para a formação do aluno e não visto apenas como números atingidos ou documentos inócuos.

\section{Referências}

ARROYO, M. G. Currículo, território em disputa. Petrópolis: Vozes, 2011.

BARDIN, L. Análise de conteúdo. Lisboa: Edições 70, 2011.

BRASIL. Lei n ${ }^{\circ}$ 9.394, de 20 de dezembro de 1996. Estabelece as diretrizes e bases da educação nacional. Brasília DF. Disponível em: $<$ http://portal.mec.gov.br/seed/arquivos/pdf/tvesc ola/leis/lein9394.pdf>. Acesso em: 20 mai. 2010.

BRASIL. Parâmetros Curriculares Nacionais. Brasília, DF: MEC, 1998.

\section{BRASIL. Indagações sobre o currículo:} currículo e avaliação. Brasília, DF: MEC, 2007.

BRASIL. Decreto $n^{\circ} 6.094$, de 24 de abril de 2007. Dispõe sobre a implementação do Plano de Metas Compromisso Todos pela Educação, pela União Federal, em regime de colaboração com Municípios, Distrito Federal e Estados, e a participação das famílias e da comunidade, mediante programas e ações de assistência técnica e financeira, visando a mobilização social 
pela melhoria da qualidade da educação básica. Brasília, 2007b. Disponível em:

$<$ http://www.planalto.gov.br/ccivil 03/ Ato20072010/2007/Decreto/D6094.htm>. Acesso em 04 jul. 2011.

BRASIL. Resolução no 4, d 13 de julho de 2010. Define diretrizes curriculares nacionais gerais para a educação básica. Brasília DF. Disponível em:

$<$ http://portal.mec.gov.br/index.php?option=com content\&view $=$ article\&id=12992\&ltemid $=866>$ >

Acesso em: 08 nov. 2011.

CASTANHO, M. E.; CASTANHO, S. E. M. Revisitando os objetivos da educação. In: Veiga, Ilma Passos Alencastro (org.). Didática: O

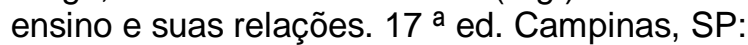
Papirus, 2010.

DINIZ, J.; AMARAL, S. C. F. A avaliação na educação física escolar: uma comparação entre as escolas tradicional e ciclada. Revista

Movimento. Porto Alegre, v. 15, n.01, p.241-258, jan./ mar. 2009.

\section{ESPÍRITO SANTO. Currículo básico escola}

estadual: guia de implementação. Secretaria de Educação. Vitória, 2009.

FREITAS, L. C. Crítica da organização do trabalho pedagógico e da didática. Campinas: Papirus, 1995.

FREITAS, L. C. Interações possíveis entre a área de currículo e a didática: o caso da avaliação.

Revista Pró- Posições. Campinas, v.9, n.3. p.28- 42, nov. 1998.

FERREIRA, A. B. H. Mini Aurélio: dicionário da língua portuguesa. 8 ed. Curitiba: Positivo, 2010.

GOODSON, I. F. Currículo: teoria e história. Petrópolis, RJ: Vozes, 1995.

KENSKI, V.M. Avaliação da aprendizagem. In: VEIGA, I.P. de A. (org.) Repensando a didática. Campinas: Papirus, 1995.

LOPES, A. C. Conhecimento escolar: ciência e cotidiano. Rio de Janeiro: UERJ, 1999.

LUCKESI, C. C. Avaliação da aprendizagem escolar: estudos e proposições. 7 ed. São Paulo: Cortez, 1998.

MACHADO, T. M. R. Organização curricular: objetivos ou competências e habilidades? Procurando a diferença entre "seis e meia dúzia". In: REUNIÃO ANUAL DA ANPED, 30, 2007, Caxambu. Anais eletrônicos...Caxambu:
ANPED, 2007.Disponível em: $<$ http://www.anped.org.br/reunioes/30ra/index.htm >. Acesso em: 10 nov. 2011.

MARTINY, L. E.; FLORÊNCIO, S. Q. N.; GOMES-DA-SILVA, P. N. O referencial curricular da educação física do Estado do Rio Grande do Sul: uma análise qualitativa de conteúdo. Pensar a Prática. Goiânia, V.14, n. 1, p. 1-14, jan./abr. 2011.

MINAS GERAIS. Currículo básico comum: educação física ensino fundamental e médio. Secretaria de Educação, s/d.

MINAYO, M. C. S. O desafio do conhecimento: pesquisa qualitativa em saúde. 8.ed.São Paulo: Hucitec, 2004.

MOREIRA, A.F. Propostas curriculares alternativas: limites e avanços. Educação \& Sociedade, p. 109-137, Dez. 2000.

NEIRA, M. G.; NUNES, M. L. F. Pedagogia da cultura corporal: críticas e alternativas. $2^{\mathrm{a}}$ ed. São Paulo: Phorte, 2008.

NEIRA, M. G. (orgs.) et al. Educação física e culturas: ensaios sobre a prática. São Paulo: FEUSP, 2012. Disponível em:

<http://www.gpef.fe.usp.br/>. Acesso em: 15 fev. 2012.

PERNAMBUCO. Governo do Estado. Secretaria de Educação, Cultura e Esportes. Base curricular comum para as redes públicas de ensino de Pernambuco - Educação física. Recife: SE-PE e UNDIME-PE, 2006 (arquivo digital PDF - Adobe Acrobat).

PILETTI, C. Didática geral. 24aㅡ ed.São Paulo: Ática, 2010.

ROMÃO, J. E. Avaliação dialógica: desafios e perspectivas. São Paulo: Cortez, 2009.

RIO DE JANEIRO. Proposta curricular: um novo formato educação física. Secretaria de Educação, Rio de Janeiro. 2010a.

RIO DE JANEIRO. Diretrizes curriculares: ensino fundamental anos iniciais. Secretaria de Educação, Rio de Janeiro. 2010b.

SACRISTÁN, J. G. O Currículo: uma reflexão sobre a prática. Porto Alegre: Artmed, 1998.

SANT'ANNA, F. M et al. Planejamento de ensino e avaliação. Porto Alegre: Sagra Luzzatto, 1998. 
SANTOS. Lucíola Licinio. Currículo em tempos difíceis. Educação em Revista. v.45, Belo Horizonte, p.291-306, jun.2007.

\section{SÃO PAULO. Currículo do Estado de São}

Paulo: linguagens, códigos e suas tecnologias. Secretaria de Educação. São Paulo, 2010.

\section{SCHMITZ, E. F. Didática moderna:}

fundamentos. Rio de Janeiro: Livros Técnicos e Científicos S. A, 1982.

\section{SEVERINO, A. J. Metodologia do trabalho}

Científico. 23. ed. São Paulo: Cortez, 2007.

SILVA, T. T. S. Documentos de identidade: uma introdução às teorias do currículo. $3^{\circ} \mathrm{ed}$. Belo Horizonte: Autêntica, 2011.

SOARES, C.L et al. Metodologia do ensino da educação física. São Paulo: Cortez, 1992.

SOUZA, C. P. A avaliação do rendimento escolar sedimentação de significado. In: SOUZA, Clarilza Prado de (org.). Avaliação do rendimento escolar. Campinas: Papirus, 2008.

SOUZA JÚNIOR, M. Praticas avaliativas e aprendizagens significativas em educação física: trajetórias, orientações legais e implicações pedagógicas. Revista Pró- Posições. Campinas, v. 15, n.2, p. 201- 217, maio/ago. 2004.

\section{SOUZA JÚNIOR M.. A constituição dos}

saberes escolares na educação básica. 2007.

354f. Tese (Doutorado em Educação) -

Universidade Federal de Pernambuco, Recife, 2007.

SOUZA JÚNIOR M. Política Curricular e Educação Física: competências, ciclos e qualidade social na proposta da Rede Municipal do Recife. In: SOUZA JúNIOR, M. (Org.) et al.

Educação física escolar: Teoria e política curricular, saberes escolares e proposta pedagógica. 2 ed. Recife: EDUPE, 2011, v. 1, p. 29-83.

SOUZA JÚNIOR, M. et al. Currículo e saberes escolares: ambigüidades, dúvidas e conflitos.

Revista Pró-Posições. Campinas, V. 22, n.1.p. 183-196, jan./abr. 2011.

TYLER, R. W. Princípios básicos de currículo e ensino. Porto Alegre: Globo, 1974.

VAGO, T. M. Início e fim do século XX: maneiras de fazer educação física na escola. Caderno

Cedes. n.48, agosto, 1999.

ZABALA, A. A prática educativa: como ensinar. Porto Alegre: Artmed, 1998.

\section{Endereço:}

Kadja Michele Ramos Tenório

Programa de Pós-Graduação em Educação Física da UPE/UFPB.

Av. São Paulo, 55/102 bloco B, Jd. São Paulo Recife PE Brasil

50.781-600

e-mail: kadjamichele@hotmail.com

Recebido em: 15 de novembro de 2011.

Aceito em: 3 de abril de 2012.

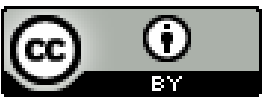

Motriz. Revista de Educação Física. UNESP, Rio Claro, SP, Brasil - elSSN: 1980-6574 - está licenciada sob Creative Commons - Atribuicão 3.0 